\title{
Da necessidade de se ler O Problema do Café no Brasil
}

\author{
Flávio Rabelo Versiani ${ }^{1}$
}

Estudos sobre a sociedade e a economia brasileira, até o terceiro quartel do século passado, tinham, na maioria, um caráter de certa forma ensaístico: visões amplas, painéis interpretativos, os mais influentes deles abrindo novos caminhos, como as obras clássicas de Gilberto Freyre, Sérgio Buarque de Holanda ou Celso Furtado. Mas a partir dos anos setenta, com a reforma universitária e a institucionalização dos cursos de pós-graduação na década anterior, as exigências de titulação para ingresso e ascensão na carreira universitária fizeram com que a produção acadêmica passasse a ser crescentemente monográfica, voltada ao estudo detalhado de questões mais específicas, frequentemente derivada de teses e dissertações defendidas nos cursos de mestrado e doutorado.

O Problema do Café no Brasil, do Prof. Delfim Netto, foi um trabalho pioneiro nessa segunda linha. Uma tese de doutorado realmente modelar: baseada em pesquisa detalhada e cuidadosa, a partir de um amplo conjunto de informações, tanto dados quantitativos quanto evidência histórica, e uso pertinente de métodos estatísticos e de modelagem microeconômica. Abrindo uma perspectiva inovadora para a compreensão da economia cafeeira no Brasil. ${ }^{2}$

1 Professor - Universidade de Brasília - Campus Universitário Darcy Ribeiro - Brasília/DF - Brasil CEP: 70910-900 - E-mail: versiani@unb.br - ORCiD: https://orcid.org/0000-0001-6254-7536.

2 A tese do Prof. Delfim Netto, de 1959, foi republicada pela Editora da Fundação Getúlio Vargas em 1979. As referências abaixo referem-se a essa edição (citada abaixo como PCB).

Editor Responsável: Dante Mendes Aldrighi

(c) (i) (\$) Esta obra está licenciada com uma Licença Creative Commons Atribuição-Não Comercial 4.0 Internacional. 
Existe, ou deve existir, uma complementaridade entre essas duas formas de abordagem. Um esquema ou estrutura de interpretação traz uma perspectiva geral de análise, um quadro de referência que pode fornecer sugestões ou diretrizes para trabalhos com foco mais específico. Por seu turno, pesquisas monográficas proporcionam uma base para a construção de modelos generalizadores, ao mesmo tempo em que podem também dar elementos para que se verifique a adequação de tais modelos à realidade factual. Se novas investigações descobrem novos fatos, é preciso, muitas vezes, que o arcabouço interpretativo mais amplo se adapte a isso, seja eventualmente corrigido ou mesmo falseado.

Essa inter-relação é tanto mais importante quanto esquemas ou estruturas de análise abrangentes podem ser muito atraentes, principalmente para o leigo ou para o iniciante em estudos históricos. Interligando vários elementos, esclarecendo relações e causações, podem dar um sentido lógico e simplificador à História. Mas essa própria atratividade encerra um perigo: o de que tais esquemas sejam vistos, por alguns, como sempre verdadeiros, no espaço e no tempo; narrativas cristalizadas, sob o escudo da autoridade intelectual de seu autor. Um antídoto contra isso são pesquisas sobre casos ou aspectos específicos: examinar as árvores para entender melhor a floresta.

Nesse ponto, o livro de Delfim Netto tem particular relevância. É óbvio o peso da produção cafeeira na economia do país, por um largo período histórico, como principal artigo de exportação e núcleo importante de investimento e geração de renda. Sendo assim, é natural que muitos ensaios interpretativos tenham abordado, de uma forma ou de outra, a economia do café. A análise detalhada de O Problema do Café no Brasil é uma rica fonte de elementos com que seja testada a validade desses esquemas mais gerais.

Como exemplo, tomemos o exame da economia cafeeira num dos modelos de análise mais conhecidos e influentes da evolução da economia brasileira, a Formação Econômica do Brasil, de Celso Furtado. Um argumento do livro 
que ficou famoso, com respeito ao café, foi o de que, quando de uma queda no preço externo do produto, haveria um mecanismo de socialização, para a coletividade, da perda que essa queda trazia para os cafeicultores (Furtado 1976[1959], caps. 27 e 28).

No argumento de Furtado, a queda no preço teria origem na crise cíclica das economias industrializadas, provocando redução nas importações, por esses países, de produtos primários, como o café; com menor demanda, caía o preço de tais produtos. Os altos e baixos dos preços de produtos primários seriam, assim, originados no exterior: "a crise penetrava [...] de fora para dentro", em países como o Brasil (ibid., p.163). Caindo o preço do café, e dado o peso do produto nas exportações brasileiras (e considerando também que a crise externa se refletia na conta financeira do balanço de pagamentos, pela retração da entrada de capitais), ocorreria uma desvalorização do mil-réis. Em consequência, o aumento no valor interno do dólar compensaria, pelo menos em parte, o efeito negativo da queda no preço externo para os cafeicultores. Por outro lado, como evidentemente as importações subiam de preço, por efeito da desvalorização, haveria uma transferência indireta de renda dos consumidores de importações (a generalidade da população, especialmente a urbana) para os empresários do café. Uma "socialização" do prejuízo destes com a queda de preço. Furtado não menciona isso, mas o argumento necessariamente se refere ao período anterior à política de "valorização" do café, a partir de 1906, quando o governo passou a intervir na determinação do preço do produto.

A questão das variações no preço externo do café, no período anterior a 1906, foi analisada detalhadamente na tese do Prof. Delfim. Foram identificados, a partir de 1857, três ciclos de aumento e redução do preço: 1857-1868 (com um pico em 1863); 1869-1885 (com um pico eml874); e 1886-1906 (pico em 1891-92). Um ponto que fica claro nessa análise é que esses movimentos de preço não resultaram apenas de ciclos de atividade econômica nos países importadores, como suposto por Furtado, mas tiveram um importante componente interno. Delfim chamou atenção para o fato de que o cafeeiro, uma planta perene que pode produzir economicamente por várias décadas, apenas atinge sua plena produção quatro ou cinco anos depois de plantado. Um aumento na demanda, fazendo subir o preço, estimulará um aumento no plantio, mas a produção dos novos cafeeiros só atingirá o mercado depois do período de maturação. Nesse ínterim, continuando presente o estímulo de preço, continuará a expansão do plantio; quando todo o aumento de oferta derivado dos novos cafezais se 
materializar, haverá tendência a uma queda no preço, tanto maior quanto mais inelástica ao preço se mostrar a demanda pelo produto. Ou seja, pode haver comportamento cíclico derivado simplesmente das condições físicas da oferta de café.

No estudo dos três ciclos mencionados, Delfim examinou em pormenor os vários fatores que provocaram alterações na demanda e na oferta de café. O primeiro ciclo, por exemplo (1857-68), foi influenciado, entre outras causas, por uma praga que atingiu os cafeeiros, fazendo reduzir a oferta, na fase ascendente do ciclo; e, na fase descendente, pela redução da demanda dos Estados Unidos, durante a guerra civil neste país. No segundo ciclo (1869-85), período de grande aumento no consumo internacional, e também de intensa expansão das plantações (na fase ascendente), observou-se, na maioria dos anos posteriores ao pico de 1874, uma redução no preço interno menor do que a do preço internacional, devido à desvalorização da moeda (trazendo a "socialização de perdas", de Furtado). Na fase ascendente do ciclo seguinte (1886-1906), contudo, houve um fenômeno inverso: o preço externo aumentou muito (mais do que duplicou, até 1890), enquanto o preço interno subia bem menos (cerca de $50 \%$, nesse período), devido à valorização do mil-réis. Quer dizer: poder-se-ia falar, aqui, simetricamente, numa "socialização dos ganhos" dos produtores e exportadores com o aumento do preço internacional do café: os empresários do café estavam perdendo receita em mil-réis, com a valorização, enquanto a generalidade dos consumidores ganhava, com o barateamento das importações.

O visto acima põe em evidência o fato de que é necessário cotejar descrições sintetizadoras, como a de Furtado nesse caso, com a evidência de estudos detalhados, como o de Delfim - e corrigir as primeiras, quando necessário, à luz dos segundos. O movimento cíclico nos preços do café não se originava só de variações na demanda externa, devidas a ciclos de atividade nos países importadores; havia também outros fatores, agindo do lado da oferta, como Delfim esclareceu. Mais importante: é inadequado destacar um aspecto apenas da inter-relação de preços e taxas de câmbio, a "socialização das perdas" (sem falar na "dos ganhos"). Isso não só dá uma ideia incompleta de tal inter-relação, como pode dar origem a percepções incorretas, como se verá a seguir.

Furtado descreveu o fenômeno da "socialização das perdas" dos cafeicultores como um mecanismo de mercado: a redução na oferta de divisas, pela retração do valor das importações (possivelmente reforçada pela redução 
na entrada de capitais) é que causaria o aumento de sua cotação, ou seja, a desvalorização da moeda nacional. Mais adiante no livro, no entanto, encontram-se afirmativas que podem ser interpretadas de modo diverso: a desvalorização seria buscada deliberadamente, com o objetivo de proteger os cafeicultores. Por exemplo, no capítulo 30 está dito que, no final da década de 1890, a conjuntura da época (ou seja, "a situação de extrema pressão sobre a massa de consumidores urbanos" consequente à grande alta do nível de preços nos anos anteriores), "tornou impraticável insistir em novas depreciações [...], impraticável apelar para o mecanismo cambial a fim de defender a rentabilidade do setor cafeeiro" (Furtado 1976[1959], p. 178). É fácil depreender, dessa asserção, a ideia de que a depreciação seria um mecanismo que podia ser acionado, quando se pretendesse proteger os cafeicultores dos efeitos de uma baixa no preço do produto.

Essa noção teve ampla difusão na literatura, especialmente na literatura não tecnicamente econômica, como livros didáticos, onde frequentemente se encontra a afirmativa de que a pressão dos interesses da cafeicultura é que levava à depreciação da moeda, quando da queda no preço externo e levava, portanto, à socialização dos prejuízos dos empresários do café. Evidência clara disso é a seguinte passagem de um livro de Fernando Henrique Cardoso que discute interpretações influentes da evolução da sociedade e da economia do Brasil. No capítulo dedicado ao livro de Furtado, Cardoso escreveu:

[Q] uando havia a queda do preço internacional do café, os fazendeiros e exportadores forçavam a depreciação da moeda, tornando as importações mais caras e defendendo o valor das exportações; como as importações eram consumidas pela massa da população e o valor das exportações permanecia nas mãos dos cafeicultores e exportadores, produzia-se o fenômeno que Furtado qualificou de "socialização das perdas", ou seja, a transferência dos prejuízos para o conjunto da população. (Cardoso 2013. p. 211).

Ou seja, o argumento original de Furtado, baseado em interações de oferta e demanda, transformou-se aqui numa narrativa inteiramente diferente: tratar-se-ia de uma decisão política de proteger o setor cafeeiro, pela intervenção do governo no mercado de câmbio - o que não era evidentemente o caso, no período considerado. O sentido dessa narrativa, como fica apa- 
rente, é pôr em relevo o poder político dos cafeicultores, influindo, em seu proveito, nas decisões do governo. Que esse poder político existia ficará claro no período posterior, após 1906, quando teve início a longa série de intervenções governamentais no mercado de café, buscando sustentar o preço externo do produto. Mas a fase anterior foi, essencialmente, de mercado livre, sem intervenções do governo nos mecanismos de mercado.

É um exemplo das armadilhas que podem conter os esquemas interpretativos amplos, como visto acima: no bojo de uma visão sintetizadora, podem surgir argumentos enganosos ou incorretos. Daí - é conveniente enfatizar outra vez - a necessidade de sempre cotejar tais visões com análises detalhadas da realidade concreta. E a necessidade, em particular, de se estudar o livro de Delfim Netto, se se quer entender o problema do café na economia brasileira.

\section{III}

Outro aspecto é a questão da elasticidade-renda da demanda por café. Tanto um empiricismo casual, quanto referência à Lei de Engel, podem levar à noção de que essa elasticidade é baixa; elevações na renda per capita nos países consumidores não trariam aumentos significativos na procura por café.

A tese da baixa elasticidade-renda de produtos alimentares e, mais geralmente, de produtos primários, teve importância central, como se sabe, no pensamento econômico latino-americano da segunda metade do século XX - o "pensamento da CEPAL", como é comum rotular-se, por referência aos trabalhos desenvolvidos por economistas ligados à Comissão Econômica da América Latina, das Nações Unidas, nesse período. E foi uma tese influente, em particular, nas prescrições de política econômica derivadas daquele pensamento.

Na formulação original, em Prebisch (1952), analisam-se as relações entre os países da "periferia", exportadores de produtos primários, entre eles os latino-americanos, e os do "centro", os países industrializados da Europa e da América do Norte, importadores de tais produtos. O aumento de ren- 
da nos países centrais produzia não só pequeno aumento de demanda por produtos alimentares, como também o progresso técnico faria com que a participação de produtos primários como matéria prima industrial fosse decrescente. Em contrapartida, a demanda por produtos industriais, na periferia, tem alta elasticidade-renda (o que deu origem à proposição de que haveria uma queda secular nas relações de troca entre os dois grupos de produto). Essa baixa-elasticidade renda das exportações podia condenar as economias da periferia a um baixo nível de crescimento: "If Latin American countries could only expand by means of primary exports, [...] their rate of economic development would be considerably lower than in the industrial centres." (Prebisch 1952, apud Bielschowsky 2016, p.111). $\mathrm{O}$ que dava suporte ao argumento em favor da industrialização substitutiva de importações, nesses países, proposição básica do pensamento da CEPAL, nas décadas posteriores ao final da Segunda Guerra.

As constatações do estudo de Delfim Netto sobre o café são muito relevantes quanto a esses argumentos: não há apoio à ideia de que a demanda internacional por café tenha elasticidade-renda reduzida. ${ }^{3}$ De fato, nas páginas de conclusão, afirma-se o oposto:

Não é possível esquecer-se [...] que o próprio desenvolvimento econômico deve elevar a potencialidade do consumo do café, que é um produto de elasticidade-renda positiva. (PCB, p. 236).

Em várias passagens, ao longo do livro, encontram-se afirmativas evidenciando um efeito positivo, sobre as exportações brasileiras de café, de aumentos de renda nos países consumidores - como na análise dos ciclos de preços, antes de 1906. No final da década de 1860, por exemplo, com a recuperação da economia europeia da crise de meados da década, de par com o fim da guerra civil nos Estados Unidos, "a curva de procura se deslocava para a direita à medida que aumentava o nível de rendimento dos consumidores do produto", marcando a fase ascendente do segundo ciclo (PCB, p.11). Por outro lado, a fase descendente desse ciclo foi afetada pela crise mundial de 1873, quando a "redução do nível de rendimento dos países consumidores" teve efeito de reduzir o ritmo de expansão do consumo. (ibid., p.12). E, no terceiro ciclo, "entre 1885 e 1890, o rendimento dos consumidores se elevava com rapidez e, portanto, a sua procura, o que,

3 A elasticidade-preço da demanda porcaféé analisada detalhadamenteno capítulo 8 do livro: PCB,pp.191-219. 
por seu turno auxiliou a alta dos preços" (ibid. p.17). Ainda: "são essas altas taxas de rendimento per capita [nos principais países da Europa e nos Estados Unidos, nas décadas finais do século XIX] que explicam o alto dinamismo da procura por café" (ibid., p.31). E, com referência a um período posterior: "É certo que não é possível dissociar-se da queda de preços ocorrida em 1921 a parte que é devida à queda do nível de rendimento nos Estados Unidos em consequência da crise" (ibid. p.173).

O interesse dessas constatações é posto em evidência quando se tem em conta que a crença na inelasticidade da demanda externa por café e, em geral, da demanda internacional por produtos agrícolas, influiu de forma significativa na política econômica do pós-Segunda Guerra, no Brasil. A suposição de que exportações agrícolas tivessem poucas perspectivas de expansão reforçava a ideia de que a industrialização era a rota única do crescimento econômico. Em certo período, vigorou também a noção de que a produção agrícola não respondia a estímulos de preço, de tal forma que, também do lado da oferta, o setor agrícola tinha poucas possibilidades de crescimento. ${ }^{4}$ Nesse contexto, as políticas econômicas, em geral estimuladora da industrialização, foram desfavoráveis, de várias formas, ao setor agrícola, como tem sido observado por analistas desse período, pela manutenção de uma taxa de câmbio valorizada, ou pelo controle de preços de produtos alimentares. $\mathrm{O}$ que opôs um sério obstáculo à diversificação das exportações agrícolas.

Com a perspectiva de 1959, o Prof. Delfim assinalava o obstáculo que uma taxa de câmbio valorizada para exportações impunha à diversificação destas. Para os produtos agrícolas em que o Brasil era um price-taker, no mercado internacional — todos, com exceção de café e cacau — "em breve chega o momento em que é impossível exportar-se, porque o preço no mercado internacional, convertido à taxa cambial em vigor, é inferior ao custo do produto no país" (PCB, p. 234).

Uma diversificação das exportações agrícolas ocorreria apenas mais tarde, nas últimas décadas do século, sob novas políticas relacionadas ao setor agropecuário. A notável expansão de novos setores agroexportadores, nessa última fase, deixou clara a incorreção de generalizações anteriores sobre a inelasticidade-renda da demanda por tais produtos. Como antevisto por Delfim, no caso do café.

4 Noção que trabalhos de colaboradores do Prof. Delfim Netto na Universidade de São Paulo contribuíram para desmentir; v., por ex., Pastore 1973. 


\section{IV}

A política de "valorização" do café pela sustentação de seu preço, em suas várias fases, foi avaliada desfavoravelmente por Delfim Netto por várias razões. Em primeiro lugar, por promover o crescimento da concorrência, por estimular o aumento da produção em outros países, fazendo com que o Brasil perdesse progressivamente participação na oferta mundial (o que é analisado no capítulo 4 do livro). E ainda por desestimular a busca por aumentos de produtividade: a manutenção de um preço lucrativo do produto possibilitava a permanência no mercado dos produtores com baixa produtividade, ao mesmo tempo que, beneficiando amplamente os que tinham alta produtividade, não os incitava à busca de novos ganhos de eficiência. Estimulava, por outro lado, a longo prazo, aumentos de produção acima da capacidade de absorção do mercado (PCB, pp.184-85). De uma perspectiva mais ampla, a defesa dos preços pode ter proporcionado ganhos de curto prazo, pela exploração do poder de monopólio do país no mercado do produto; no entanto, provavelmente determinou, a longo prazo, uma alocação ineficiente de fatores de produção, internamente, pelo menor desenvolvimento de outras atividades produtivas (ibid., p.190).

A perda pelo não crescimento de outras produções exportadoras pode ser expressa, por exemplo, pelo fato de que a participação de exportações no PIB brasileiro tenha passado de 20,6\% em 1906, quando se iniciou a política de sustentação do preço do café, para 3,3\% em 1964, quando o produto perdeu sua posição dominante nas exportações do país (Bacha 2019).

É bem possível que o Prof. Delfim mantivesse, hoje, sua avaliação negativa sobre o conjunto da política de intervenção do governo no mercado de café, que se estendeu até 1990, quando foi extinto o Instituto Brasileiro do Café. Isso estaria de acordo com suas convicções liberais, expressas, por exemplo, em artigo de 1977, onde argumentou que a intervenção do Estado na economia seria necessária apenas para a consecução de dois objetivos: minimizar flutuações no produto e no emprego, e reduzir desigualdades distributivas (Delfim Netto 1986, pp. 110-12). 
Voltando ao argumento inicial: no estudo da evolução da economia brasileira, é preciso que haja um balanço entre, de um lado, modelos históricos abrangentes, que podem fornecer um arcabouço para o correto entendimento de situações e fenômenos particulares, e suas inter-relações; e, de outro lado, análises detalhadas de tais situações e fenômenos. Nessa perspectiva, é preciso que O Problema do Café no Brasil seja lido, talvez mais lido por estudantes de Economia e de outras Ciências Sociais, para que compreendam melhor como e por que o café teve papel tão central na economia e na política econômica do país. E, provavelmente mais importante, como e por que uma política cafeeira aparentemente contrária aos interesses maiores do país pôde ser seguida por quase um século.

\section{Referências}

Bacha, E. “A Valorização do Café e seu Amargo Legado". Texto para Discussão n 54. Rio de Janeiro: Instituto de Estudos de Política Econômica, 2019.

Bielschowsky, R.(org.). ECLAC Thinking: Selected Texts (1948-1998). New York: United Nations, 2016.

Cardoso, F.H. Pensadores que Inventaram o Brasil. São Paulo: Companhia das Letras, 2013.

Delfim Netto, A. O Problema do Café no Brasil. Rio de Janeiro: Editora da Fundação Getúlio Vargas, 1979[1959].

Delfim Netto, A. "Em Defesa do Regime de Livre Iniciativa”. Em: Só o Político Pode Salvar o Economista. Rio de Janeiro: Edição do Autor, 1986.

Furtado, C. Formação Econômica do Brasil. 14ed. São Paulo: Cia. Editora Nacional, 1976[1959].

Pastore, A.C. A Resposta da Produção Agrícola aos Preços no Brasil. Rio de Janeiro: APEC, 1973.

Prebisch, R. Theoretical and Practical Problems of Economic Growth. Santiago: ECLA, 1952. 